\title{
Toponímia e línguas indígenas: um estudo de caso com base na toponímia sul-mato-grossense
}

\author{
Toponymy and indigenous languages: a case study based on the toponymy sul-mato-
}

grossense

\author{
Camila André do Nascimento da SILVA* \\ Universidade Federal de Mato Grosso do Sul (UFMS) \\ Aparecida Negri ISQUERDO** \\ Universidade Federal de Mato Grosso do Sul (UFMSCNPq)
}

RESUMO: Este trabalho discute aspectos da contribuição vocabular ameríndia em designativos toponímicos que nomeiam acidentes físicos e humanos da zona rural da microrregião de Paranaíba/MS. O corpus analisado foi extraído do Sistema de Dados do ATEMS (Atlas Toponímico do estado de Mato Grosso do Sul), complementado por dados oficiais do IBGE/2010. A análise dos dados foi orientada pelo modelo teórico-metodológico de Dick (1990; 1992). Para as questões de natureza etimológica e de língua de origem dos topônimos, foram consultadas obras lexicográficas de línguas indígenas, tais como Sampaio (1928); Tibiriçá (1985; 1989); Navarro (2013) e Cunha (1999). Os resultados confirmam que a toponímia indígena examinada evidencia aspectos da influência de fatores de natureza física na nomeação dos acidentes geográficos. Em relação à língua de origem dos topônimos os dados evidenciaram a predominância do português e uma presença significativa de topônimos oriundos de línguas indígenas, com maior incidência do Tupi.

PALAVRAS-CHAVE: Onomástica. Toponímia indígena. Léxico. Mato Grosso do Sul.

ABSTRACT: This paper discusses aspects of Amerindian vocabulary contribution in toponymic designations that name physic and human geographic accidents in the rural area, of the micro region of Paranaíba/MS. The analyzed corpus was obtained from the database ATEMS (Atlas of the State of Mato Grosso do Sul), complemented by official data from IBGE/2010. Data analysis was oriented theoretical-methodological model by Dick (1990; 1992). About questions of etymological nature and language of origin of the toponyms, lexicographic works of indigenous languages were consulted, such as: Sampaio (1928); Tibiriça

* Doutoranda em Letras pela Universidade Federal de Mato Grosso do Sul, campus de Três Lagoas/MS UFMS/CPTL. E-mail: camilandreufms@ @otmail.com.

** Doutora em Letras pela UNESP/Araraquara (1996). Docente aposentada pela Universidade Federal de Mato Grosso do Sul. Atua como Professora Visitante na Pós-Graduação stricto sensu da UFMS: Estudos de Linguagens/FAALC e Letras/CPTL. E-mail: aparecida.isquerdo@gmail.com.

Revista Moara, n. 55, jan-jul 2020 ISSN: 0104-0944

Recebido em 26/03/2020

Avaliado em 15/06/2020 
(1985; 1989); Navarro (2013) and Cunha (1999). The results confirm that the indigenous toponymy examined highlights aspects of the influence of physical factors in the naming of geographical accidents. In relation to the source language of toponyms the data showed the predominance of Portuguese was registered and a significant presence of toponyms from indigenous languages, with a higher incidence of Tupi.

KEYWORDS: Onomastic. Indigenous toponymy. Lexicon. Mato Grosso do Sul.

\section{Introdução}

Refletir sobre a configuração da toponímia no Brasil é também reportar-se às raízes da formação da sociedade brasileira e considerar a multiplicidade de línguas e de culturas que conviveram entre si em graus distintos de interinfluências, particularmente nos primeiros séculos da colonização, e que se entrecruzaram e se amalgamaram dando origem à variedade brasileira da língua portuguesa. Assim, nesse contexto a toponímia brasileira também reflete essa realidade à medida que, além da herança lusitana, incorpora a influência de diferentes línguas indígenas, africanas e de outras línguas estrangeiras de povos que aportaram no território brasileiro. Segundo Dick (1992, p. 8), o estudo toponímico comporta considerações referentes a três adstratos linguísticos: o português, o africano e o indígena. A presença marcante de nomes indígenas na toponímia justifica o fato de as primeiras pesquisas toponímicas no Brasil terem recebido "um enfoque de natureza ameríndia", considerando-se que a influência indígena representa um diferencial da toponímia brasileira (DICK, 1994, p. 435).

Nesse cenário não pode ser desconsiderado o fato de haver entre as diferentes etnias indígenas um sentimento nacionalista considerado vencido por muitos estudiosos da área. Sampaio (1928, p. I e II), todavia, entendia que "da raça americana, vencida, nem tudo se perdeu e que se, no sangue dos descendentes, a dosagem diminui a se apagar, a memória dos primitivos íncolas perdurará com os nomes dos lugares onde a civilização ostenta os seus triunfos", evidenciando que "a predileção do brasileiro pelos nomes indígenas na denominação dos lugares é hoje tão acentuada que a toponímia primitiva vai aos poucos se restaurando e às localidades novas dão-se de preferência nomes tirados da língua dos ameríndios tupis" (SAMPAIO, 1928, p. I). 
Bordoni (s/d. p. 11), por sua vez, nessa mesma óptica, considera que "a frequência com que são usadas palavras da língua TUPI para denominar acidentes geográficos na nossa geografia afiança, de muito, a importância desta no conceito do povo brasileiro". Na perspectiva do mesmo autor,

As línguas dos povos de cultura primitiva em extinção ou não fazem parte de um acervo cultural, indispensável para qualquer nação civilizada que tem consideração pelas suas raízes históricas e que zela pela imortalidade do que há de mais autêntico e puro, que é o complexo de usos, costumes e falares de seus antepassados (BORDONI, s/d, p. 11).

\section{A Toponímia: considerações}

Os estudos sobre a toponímia tiveram início na França, por volta de 1878, com os trabalhos de Longnon e tinham como objetivo recuperar a etimologia dos nomes, ou seja, apenas o dado linguístico era foco de investigação toponímica (DICK, 1992, p. 1). Ainda segundo a mesma autora, em 1922, a obra de Dauzat muda o rumo dos estudos toponímicos ao propor a investigação do fato linguístico, à medida que tinha como propósito examinar, além da etimologia, o significado da unidade lexical investida de função toponímica, o topônimo. As contribuições de Dauzat (1922) serviram, ao longo do século XIX, para consolidar e expandir as pesquisas toponímicas na Europa e em outros continentes (DICK, 1992, p. 1). Enfim, coube aos franceses Longnon e Dauzat o mérito de despertar o interesse pelas pesquisas toponímicas no âmbito dos estudos linguísticos.

No Brasil, Cardoso (1961) e Drumond (1965) deram os primeiros impulsos aos estudos da toponímia indígena, mas foi a partir de 1980, com a defesa da Tese de Doutorado de Maria Vicentina de Paula do Amaral Dick ${ }^{1}$, na Universidade de São Paulo, sob a orientação de Carlos Drumond, que a pesquisa toponímica ganha novo elã no Brasil.

Dick (1990, p. 36) esclarece que, como ramo da Onomástica, a Toponímia estuda a significação dos nomes de lugares, considerando também possíveis influências de aspectos geográficos, históricos, socioeconômicos e antropolinguísticos que

\footnotetext{
1 Título da Tese: A motivação toponímica. Princípios teóricos e modelos taxionômicos. O trabalho foi publicado em 1990 com o título Motivação toponímica e a realidade brasileira, versão consultada para este estudo.
} 
motivaram o surgimento de nomes de lugares e a sua subsistência. Para a autora, a Toponímia é uma disciplina vinculada à ciência linguística que tem como objetivo investigar o léxico toponímico de uma região, considerando-o como expressão linguístico-cultural de um determinado grupo social, existente ou preexistente, na área geográfica que abriga o topônimo, tendo em conta, na medida do possível, o resgate da possível atitude do homem no ato de nomeação.

Isso porque, conforme Dick (1990), a nomeação de um lugar não se dá de maneira aleatória, razão pela qual pode revelar informações significativas em relação à língua em uso na região no ato da nomeação e aos costumes e valores do denominador. Além disso, a toponímia pode revelar acontecimentos históricos e influências decorrentes do contato entre grupos étnicos. $\mathrm{Na}$ próxima seção, são tecidas considerações específicas a respeito da toponímia indígena.

\section{A toponímia indígena}

O estudo da toponímia brasileira demanda também considerações acerca do adstrato da língua dos colonizadores do território; do substrato linguístico dos povos autóctones e dos adstratos das demais línguas faladas por todos os povos que fizeram parte da formação histórica do povo brasileiro, tendo em vista que

\footnotetext{
A formação etno-histórica do Brasil acusa a existência de estratos populacionais diversos como os ameríndios, distribuídos em vários troncos, os portugueses, os africanos, e os de procedência estrangeira, já em época posterior à colonização propriamente dita. Essa origem heterogênea deixou reflexos diferenciados na língua, nos usos e costumes, nas tradições regionais e, consequentemente, na toponímia do país (DICK, 1982, p. 75).
}

Na verdade, Dick (1982, p. 75) parte do princípio de que "a ocorrência de falantes distintos no território brasileiro acabaria por marcar, também distintamente, a toponímia local”. Quando os europeus chegaram ao Brasil, depararam-se com uma nomenclatura indígena básica que foi incorporada à toponímia que então se constituiu, razão pela qual “a toponímia portuguesa envolve características históricas peculiares, porque veio em substituição à uma nomenclatura indígena já estabelecida”. Além disso, é preciso ter em conta a presença dos "nomes transplantados", ou seja, o "designativo geográfico que existe como tal em um determinado espaço e que passa a integrar a 
nomenclatura de outra região qualquer, trazido pelo próprio povo que emigrou, ou influenciado por um mero mimetismo" (DICK, 1982, p. 83) 2 .

A nomeação, conforme Dick (1990), configurava-se como uma atividade cotidiana para os europeus na "descoberta" de novos povos e de realidades no continente recém-descoberto. À época da colonização das terras brasileiras, os colonizadores portugueses tinham urgência em demarcar o novo território e, consequentemente, imprimir a marca da colonização lusitana no novo "paraíso". Nesse processo, topônimos de origem indígena foram apagados, reorganizados e um grande contingente de acidentes geográficos foram rebatizados, com o objetivo de conferir à nova terra "marcas" lusitanas ${ }^{3}$. A esse respeito, Sampaio (1928, p.34) esclarece que

Denominações geográficas, explicáveis e naturalíssimas numa época em que o tupi era a língua geral ou a mais falada no país, são agora para as modernas gerações verdadeiros enigmas que as alterações cotidianas ou as inevitáveis corruptelas vão tornando indecifráveis. Portanto, preservar-lhes a grafia verdadeira, e a verdadeira pronúncia, fixar-lhes o significado, interpretado através do véo obscuro dos metaplasmos, vale tanto como resguardar um monumento histórico.

Nessa perspectiva, é possível considerar que a toponímia indígena no Brasil foi estruturada a partir de elementos formadores da etnia brasileira, uma vez que as denominações dos acidentes geográficos são tão mestiças e heterogêneas quanto o próprio povo.

\section{Questões metodológicas}

O estado de Mato Grosso do Sul (MS), localizado no sul da região Centro-Oeste do Brasil, abriga 79 municípios e 165 distritos, distribuídos por quatro mesorregiões que, por sua vez, reúnem onze microrregiões ${ }^{4}$. A microrregião de Paranaíba, universo deste estudo, pertence à mesorregião do Leste de Mato Grosso do Sul e o seu território

\footnotetext{
2 Cf. a respeito de nomes transplantados Isquerdo e Figueiredo (2012).

3 Cf. Isquerdo (2016) sobre a herança lusa na toponímia da região Norte do Brasil.

4 A Divisão Regional do Brasil em mesorregiões e microrregiões geográficas foi aprovada pela Presidência do Instituto Brasileiro de Geografia e Estatística (IBGE) por meio da Resolução PR-51 de 31 de julho de 1989. Em 2017, o IBGE lançou uma nova Divisão Regional a partir de outros referenciais denominadas, respectivamente, como regiões geográficas intermediárias e regiões imediatas.
} 
abriga quatro municípios: Aparecida do Taboado, Inocência, Paranaíba e Selvíria $(\text { IBGE/1990) })^{5}$.

Como já assinalado, este trabalho analisa um recorte da toponímia indígena do estado de Mato Grosso do Sul, centrando-se no exame de topônimos que nomeiam acidentes físicos e humanos da área rural dos quatro municípios localizados na microrregião de Paranaíba, tendo como fonte o Sistema de Dados do Projeto ATEMS ${ }^{6 .}$. Sublinhe-se que o Projeto ATEMS orienta-se, fundamentalmente, pelo modelo teóricometodológico de Dick (1990; 1992). O Sistema de Dados informatizado que abriga o corpus do projeto foi desenhado com base nos itens da ficha lexicográfico-toponímica do Projeto ATEMS que, por sua vez, resultou da adaptação do modelo original de Dick (2004) às necessidades do projeto. Para cada topônimo catalogado a partir de pesquisa nos mapas oficiais do Instituto Brasileiro de Geografia e Estatística ${ }^{7}$ foi preenchida uma ficha. A análise dos dados aqui apresentada foi orientada pelas mesmas diretrizes metodológicas adotadas pelo Projeto ATEMS. Assim, o conjunto de topônimos em exame, em termos de motivação, foi classificado segundo o modelo de Dick (1992, p. $31-34)^{8}$.

O exame dos dados analisados do ponto de vista da estrutura do sintagma toponímico considerou as situações em que a presença indígena se manifesta no elemento específico do sintagma, ou seja, no topônimo propriamente dito: i) em topônimos de estrutura morfológica simples (Rio Paranaíba; Fazenda Sabiá) e/ou como primeiro elemento de topônimos compostos híbridos (Fazenda dos Cupins da Matinha; Fazenda Capão Grande), casos em que, na estrutura do sintagma toponímico, o formante de base indígena configura-se como o elemento básico para fins de classificação do topônimo em termos semânticos, segundo Dick (1990; 1992); ii) topônimos compostos híbridos em que o formante de origem indígena figura como

\footnotetext{
5 Os dados analisados neste artigo foram coletados do Sistema de dados do Projeto ATEMS em 2017.

6 Trata-se de resultados preliminares de uma pesquisa em desenvolvimento, como tese de Doutorado, vinculada ao Projeto ATEMS, que tem como objeto de investigação a toponímia indígena sul-matogrossense.

7 A respeito da metodologia do projeto ATEMS, mais especificamente a ficha lexicográfico-toponímica do projeto ATEMS consultar Dargel e Isquerdo (2020).

8 O modelo taxionômico de Dick (1992, p. 31-34) contém 27 categorias, distribuídas em dois grandes campos: Taxionomia de natureza física (11 taxes) que remetem a motivações oriundas do meio ambiente em todos os aspectos que compõem sua formação - rios, córregos, dimensões, formações topográficas, árvores, animais etc.; Taxionomias de natureza antropocultural (16 taxes) que contemplam manifestações psíquicas, sociais e culturais do homem inserido num espaço social.
} 
segundo elemento do composto, ou seja, como termo especificador no âmbito do sintagma toponímico (Fazenda Vale do Sucuri; Retiro Curva do Maracujá; Sítio Cantar do Sabiá.

Considerando esse quadro, foram adotadas duas perspectivas de agrupamento dos dados para fins de análise. A primeira foi destinada aos dados que se enquadram na categoria "i" apresentada no parágrafo anterior, ou seja, topônimos cuja estrutura favorece a análise da motivação, segundo o constructo teórico de Dick (1992), já que a classificação taxionômica dos topônimos toma como parâmetro o primeiro elemento do topônimo no caso de nomes compostos, no caso deste estudo de base indígena. A segunda perspectiva, por sua vez, considera os topônimos compostos híbridos em que o elemento indígena tem a função especificadora (categoria “ii”, aqui considerada). Topônimos com essa configuração ocorreram de forma significativa no corpus analisado e foram reunidos no Quadro 1 apresentado no Item 4, a seguir.

Sublinhe-se, por fim, que o conjunto de topônimos de cada município que se enquadra na categoria "i" foi organizado por meio de tabelas que informam a distribuição quantitativa dos dados segundo o tipo de acidente nomeado e de acordo com a taxe toponímica (DICK, 1992, p. 31-34) (Item 4). Na sequência, os dados são discutidos em termos qualitativos, considerando a taxe toponímica a que se enquadraram (Item 4).

\section{Análise dos dados do corpus}

Os topônimos que nomeiam acidentes humanos e físicos rurais circunscritos aos quatro municípios que integram a microrregião de Paranaíba/MS somam 2.550 designativos - $1.740(\mathbf{6 8 . 2 3} \%)$ que nomeiam acidentes humanos (fazendas, retiros, sítios, chácaras etc.) e $\mathbf{8 1 0}(\mathbf{3 1 . 7 7 \%})$ que denominam acidentes físicos (rios, córregos, cachoeiras, montes, ilhas etc). Dos 2.550 topônimos, 2.276 (89.25\%) têm como língua de origem o português e 274 (10.75\%) originam-se de línguas indígenas (especificamente, do Tupi) e são subdivididos em 160 (58.39\%) acidentes humanos e 114 (41.61\%) acidentes físicos. A distribuição desses dados é apresentada na sequência, distribuídos segundo o município a que se vinculam. 


\subsection{Aparecida do Taboado}

O município de Aparecida do Taboado abriga um montante de 462 topônimos, 375 topônimos de natureza humana e 87 de natureza física dos quais 44 são de base indígena. A Tabela 1 reúne os topônimos com marca indígena distribuídos conforme o tipo de acidente nomeado - $\mathbf{1 0}$ que nomeiam acidentes físicos e $\mathbf{3 4}$ acidentes humanos e segundo a taxionomia de Dick (1992). Na sequência os topônimos analisados são reunidos segundo a taxionomia a que se vinculam.

Tabela 1: Distribuição quantitativa dos topônimos indígenas de Aparecida do Taboado/MS, segundo o tipo de acidente nomeado e a taxionomia toponímica (DICK, 1992, p. 31-34)

\begin{tabular}{l|c|l|c}
\hline \multicolumn{1}{c|}{ Acidentes Físicos } & Número & \multicolumn{1}{c}{ Acidentes Humanos } & Número \\
\hline Zootopônimos & 6 & Fitotopônimos & 14 \\
\hline Fitotopônimos & 3 & Zootopônimos & 14 \\
\hline Hidrotopônimo & 1 & Ecotopônimo & 1 \\
\hline & & Hidrotopônimo & 1 \\
\hline & & Etnotopônimo & 1 \\
\hline & & Sociotopônimo & 1 \\
\hline \multicolumn{1}{c|}{ Total } & & Não classificados & 2 \\
\hline
\end{tabular}

Fonte: Elaboração das autoras

1. Zootopônimos ("topônimos de índole animal") (DICK, 1992, p. 32) - 20 ocorrências: Fazenda Seriema; Fazenda Jandaia; Fazenda Urutu; Fazenda Cutia; Fazenda Mutum; Fazenda dos Cupins; Fazenda Mandaguari; Fazenda Tangará; Fazenda Cateto Alegre; Fazenda Sabiá; Fazenda Caramuru; $\varnothing^{9}$ Cupins; Fazenda dos Cupins da Matinha; Fazenda dos Cupins de Três Barras; Fazenda do Cateto; Córrego da Arara; Córrego Cupins; Córrego dos Cupins; Rural do Cateto e Córrego Urutu.

2. Fitotopônimos ("topônimos de índole vegetal") (DICK, 1992, p. 31) - 17 ocorrências: Fazenda Buriti; Fazenda dos Ypês; Sítio Sucupira; Fazenda Cambaúva; Fazenda Bacuri; Fazenda Guariroba; Fazenda Ipê; Fazenda Cajá; Fazenda Bacuri; Sítio da Pindaíba; Sítio Imbaúba; Fazenda Imbaúba; Fazenda Aroeira; Fazenda Capão Grande; Ilha do Sapé; Córrego Congonha e Cabeceira dos Capões.

${ }_{9}$ Acidente geográfico não registrado no mapa.

Revista Moara, n. 55, jan-jul 2020 ISSN: 0104-0944

Recebido em 26/03/2020

Avaliado em 15/06/2020 
3. Hidrotopônimos ("topônimos resultantes de acidentes hidrográficos em geral" (DICK, 1992, p. 31) - duas ocorrências: Fazenda Paraná e Rio Paraná (Grande).

4. Ecotopônimos ("topônimos relativos às habitações de um modo geral") (DICK, 1992, p. 33) - uma ocorrência: Fazenda Taperão.

5. Sociotopônimos ("topônimos relativos às atividades profissionais, aos locais de trabalho...") (DICK, 1992, p. 34) - uma ocorrência: Fazenda Jangadeiro.

6. Etnotopônimos ("topônimos referentes aos elementos étnicos, isolados ou não" (DICK, 1992, p. 33) - uma ocorrência: Fazenda Xingu.

7. Não classificados ${ }^{10}$ - duas ocorrências: Sítio Arapó e Fazenda Cabajá.

\subsection{Inocência}

O montante de $\mathbf{7 3 7}$ topônimos pertencentes ao município de Inocência assim se distribuem em termos da natureza do acidente nomeado: 451 topônimos de natureza humana e $\mathbf{2 8 6}$ de natureza física, dentre os quais $\mathbf{7 5}$ são formados com itens lexicais de língua indígena que, na Tabela 2, foram também organizados conforme o tipo de acidente nomeado (físico e humano) - $\mathbf{3 7}$ que denominam acidentes físicos e $\mathbf{3 8}$ acidentes humanos - e conforme a taxionomia (DICK, 1992).

Tabela 2: Distribuição quantitativa dos topônimos indígenas de Inocência/MS, segundo o tipo de acidente nomeado e a taxionomia toponímica (DICK, 1992, p. 31-34)

\begin{tabular}{l|c|l|c}
\hline \multicolumn{1}{c|}{ Acidentes Físicos } & Número & \multicolumn{1}{c|}{ Acidentes Humanos } & Número \\
\hline Zootopônimos & 16 & Zootopônimos & 12 \\
\hline Fitotopônimos & 16 & Fitotopônimos & 12 \\
\hline Hidrotopônimos & 1 & Etnotopônimos & 4 \\
\hline Ergotopônimos & 2 & Antropotopônimos & 3 \\
\hline Ecotopônimos & 2 & Corotopônimos & 2 \\
\hline & & Geomorfotopônimos & 2 \\
\hline & & Ergotopônimo & 2 \\
\hline \multicolumn{1}{c|}{ Total } & & Ecotopônimos & 1 \\
\hline & $\mathbf{3 7}$ & & $\mathbf{3 8}$ \\
\hline
\end{tabular}

Fonte: Elaboração das autoras.

10 "Não classificados" em virtude de ausência de fonte confiável acerca do significado do item lexical que deu origem ao topônimo na língua de origem.

Revista Moara, n. 55, jan-jul 2020 ISSN: 0104-0944

Recebido em 26/03/2020

Avaliado em 15/06/2020 
1. Zootopônimos ("topônimos de índole animal") (DICK, 1992, p. 32) - 28 ocorrências: Fazenda Jararaca; Fazenda Jararaca I; Fazenda Jararaca de Antônio Eloi A. Dias; Fazenda Jaú; Fazenda Maritaca; Fazenda Mutunzinho; Fazenda Mutum; Fazenda Perdiz; Fazenda Saracura; Fazenda Seriema; Fazenda Suçuarana; Fazenda Urutu; Córrego Inhaúma; Córrego da Mutuca; Córrego da Ouricaca; Córrego das Araras; Córrego do Arapuá; Córrego do Mutum; Córrego do Mutunzinho; Córrego do Tamanduá; Córrego do Tatu; Córrego dos Mutuns; Córrego Jararaca; Córrego Matuzinho; Rio Sucuriú; Córrego Sucurizinho; Córrego Quati e Córrego Jacaré.

2. Fitotopônimos ("topônimos de índole vegetal") (DICK, 1992, p. 31) - 28 ocorrências: Fazenda Bacuri; Fazenda Buritizal; Fazenda Indaiá; Fazenda Inhame; Fazenda Ipê; Fazenda Jacuba; Fazenda Japecanga; Fazenda Jatobá; Fazenda Samambaia; Fazenda Samambaia; Fazenda Taboca; Sítio Taboca; Córrego Buritizinho; Córrego Capão Limpo; Córrego da Mangaba; Córrego das Macaúbas; Córrego das Tabocas; Córrego do Buriti (2); Córrego do Capão Alto; Córrego do Carandá; Ribeirão Indaiá Grande; Córrego do Buritizal; Córrego Capoeira; Córrego da Goiaba; Rio Indaiá Grande; Córrego Pindaibinha e Córrego Japecanga.

3. Etnotopônimos ("topônimos referentes aos elementos étnicos, isolados ou não" (DICK, 1992, p. 33) - quatro ocorrências: Fazenda Guaicurus; Fazenda Guaicurus; Fazenda Guarani e Fazenda Marambaia.

4. Ergotopônimos ("topônimos relativos aos elementos da cultura material") (DICK, 1992, p. 33) - quatro ocorrências: Fazenda Cauim; Fazenda Muquem II; Córrego do Tereré e Córrego Moquém.

5. Antropotopônimos ("topônimos relativos aos nomes próprios individuais") (DICK, 1992, p. 32) - três ocorrências: Fazenda Jurema; Fazenda Jurema e Fazenda Taiara.

6. Ecotopônimos ("topônimos relativos às habitações de um modo geral") (DICK, 1992, p. 33) - três ocorrências: Fazenda Tapera e Córrego Tapera (2).

7. Geomorfotopônimos (“topônimos relativos às formas topográficas”) (DICK, 1992, p. 31) - duas ocorrências: Fazenda Bocaina (2). 
8. Corotopônimos ("topônimos relativos aos nomes de cidades, países, estados, regiões e continentes") (DICK, 1992, p. 32) - duas ocorrências: Fazenda Camapuã e Fazenda Ibitinga.

9. Hidrotopônimos ("topônimos resultantes de acidentes hidrográficos em geral" (DICK, 1992, p. 31) - uma ocorrências: Córrego do Paraúna

\subsection{Paranaíba}

O município de Paranaíba, segundo o Sistema de Dados do Projeto ATEMS, reúne 1.141 topônimos que assim se distribuem em termos da natureza do acidente nomeado: 812 topônimos de natureza humana e 329 de natureza física, dentre eles, 129 são de base indígena. A Tabela 3 reúne em termos quantitativos o montante de topônimos indígenas que estão distribuídos segundo a natureza do acidente nomeado (físico e humano) - $\mathbf{5 1}$ nomes de acidentes físicos e $\mathbf{7 8}$ designativos de acidentes humanos - e de acordo com o modelo taxionômico de Dick (1992).

Tabela 3: Distribuição quantitativa dos topônimos indígenas de Paranaíba/MS, segundo o tipo de acidente nomeado e a taxionomia toponímica (DICK, 1992, p. 31-34).

\begin{tabular}{l|c|l|c}
\hline \multicolumn{1}{c|}{ Acidentes Físicos } & Número & Acidentes Humanos & Número \\
\hline Fitotopônimos & 27 & Zootopônimos & 29 \\
\hline Zootopônimos & 13 & Fitotopônimos & 30 \\
\hline Hidrotopônimos & 3 & Hidrotopônimos & 3 \\
\hline Ecotopônimos & 2 & Mitotopônimos & 5 \\
\hline Corotopônimo & 3 & Litotopônimos & 1 \\
\hline Etnotopônimo & 1 & Etnotopônimos & 2 \\
\hline Mitotopônimo & 1 & Ergotopônimos & 4 \\
\hline Não Classificado & 1 & Corotopônimo & 2 \\
\hline \multicolumn{1}{c|}{ Total } & $\mathbf{5 1}$ & Não Classificado & $\mathbf{7 8}$ \\
\hline
\end{tabular}

Fonte: Elaboração das autoras. 
1. Fitotopônimos ("topônimos de índole vegetal") (DICK, 1992, p. 31) - 57 ocorrências: Fazenda Aroeira (2); Fazenda da Aroeira (2) ${ }^{11}$; Fazenda Bacuri (3); Fazenda dos Bambus; Fazenda Buriti; Fazenda do Buriti; Fazenda Cambará; Fazenda da Guariroba; Fazenda Indaiá; Fazenda Ipê da Serra; Fazenda Jatobá; Fazenda Macaúba; Fazenda Macumã; Fazenda do Mucujé; Fazenda da Mumbeca; Fazenda da Mumbequinha; Fazenda Peroba; Fazenda Pindorama; Fazenda Pindorama II; Fazenda Sapé (2); Fazenda do Sapé; Fazenda Taboca; Fazenda da Taboca (2); Fazenda do Tamburi; Córrego Macaúba; Córrego Sapé (2); Córrego Buriti; Córrego Capão (2); Córrego Capoeira; Ilha Sapé; Córrego Jeribá; Córrego Macaúba; Córrego Maracujá; Córrego Mumbequinha; Córrego Tamburi; Córrego do Capão Limpo; Córrego do Cipó; Córrego do Mucujê; Córrego Mucujê; Córrego Mucujezinho; Córrego da Ouricana; Córrego Pindaíba; Córrego Samambaia; Córrego da Taboca (2); Córrego da Taboquinha; Córrego Mumbeca; Córrego da Mumbeca e Córrego da Mumbequinha.

2. Zootopônimos ("topônimos de índole animal") (DICK, 1992, p. 32) - 42 ocorrências: Fazenda Arerê, Fazenda Ariranha, Fazenda Ariranha de Agenor F. de Oliveira; Fazenda Ariranha de Anibal Vilela; Fazenda Ariranha de Euclides Garcia; Fazenda Ariranha de João Chaves; Fazenda Ariranha de João Rosa; Fazenda Ariranha de Manuel Ferreira; Fazenda Ariranha de Maria C. de Jesus; Fazenda Ariranha de Pedro Orci; Fazenda Cateto; Fazenda Curicaca; Fazenda Irara (4); Fazenda Irara de José A. Macedo; Fazenda Irara de José Modesto, Fazenda Irara de Manuel Vidal, Fazenda Irara de Peri Modesto, Fazenda Irara de Sebastião Modesto; Fazenda da Irara (2); Fazenda Morumbi; Fazenda Mutum; Fazenda Mutum I; Fazenda dos Mutuns; Fazenda do Ouricana; Fazenda Tangará; Lagoa Areré; Córrego Areré; Rio Ariranha; Córrego Curica; Córrego da Curicaca; Ribeirão do Cancã; Córrego dos Tatus; Córrego Jataí; Córrego Mutuca (2); Córrego Mutuns; Córrego Quati e Córrego Irara.

3. Corotopônimos ("topônimos relativos aos nomes de cidades, países, estados, regiões e continentes") (DICK, 1992, p. 32) - sete ocorrências: Fazenda Itapoâ; Córrego Pindorama (2); Fazenda Guanabara (2); Retiro Guanabara e Fazenda Piracicaba.

\footnotetext{
11 No município de Paranaíba há quatro fazendas nomeadas com o topônimo Aroeira, duas sem preposição (Fazenda Aroeira) e duas com a preposição (Fazenda da Aroeira). Esclarece-se que todos os topônimos repetidos foram contabilizados de acordo com o número de ocorrências por nomearem propriedades diferentes com o mesmo nome, de acordo com os mapas do IBGE.
} 
4. Hidrotopônimos ("topônimos resultantes de acidentes hidrográficos em geral" (DICK, 1992, p. 31) - seis ocorrências: Fazenda Ipanema (2); Fazenda do Paraúna; Rio Paranaíba; Córrego Parauna e Rio Paraná.

5. Mitotopônimos ("topônimos relativos às entidades mitológicas”) (DICK, 1992, p. 33) - seis ocorrências: Fazenda Tamandaré (2); Sítio Tamandaré; Fazenda Tamandaré de Manuel Paula; Fazenda Tamandaré de Otavio Simões e Córrego Tamandaré.

6. Etnotopônimos ("topônimos referentes aos elementos étnicos, isolados ou não (povos, tribos, castas))" (DICK, 1992, p. 33) - três ocorrências: Fazenda Aimoré; Fazenda Indiana e Córrego Cuete.

7. Ergotopônimos ("topônimos relativos aos elementos da cultura material") (DICK, 1992, p. 33) - duas ocorrências: Fazenda Jangada e Sítio Tupia.

8. Ecotopônimos ("topônimos relativos às habitações de um modo geral") (DICK, 1992, p. 33) - duas ocorrências: Córrego Tapera Velha e Córrego Tapera.

9. Litotopônimos ("topônimos de índole mineral, relativos também à constituição do solo") (DICK, 1992, p. 31-32) - uma ocorrência: Fazenda Itauna.

10. Não classificados - três ocorrências: Fazenda Araute; Fazenda Morimolo e Córrego Jaraguaiá.

\subsection{Selvíria}

Esse município abriga 210 designativos assim distribuídos conforme a natureza do acidente geográfico nomeado: 102 topônimos de natureza humana e 108 de natureza física, dentre os quais, 26 são de base indígena. Na Tabela 4, foram disponibilizados os topônimos de origem indígena assim distribuídos conforme o acidente nomeado - $\mathbf{1 6}$ nomes de acidentes físicos e $\mathbf{1 0}$ designativos de acidentes humanos - e de acordo com taxionomia toponímica (DICK, 1992). 
Tabela 4: Distribuição quantitativa dos topônimos indígenas de Selvíria/MS, segundo o tipo de acidente nomeado e a taxionomia toponímica (DICK, 1992, p. 31-34)

\begin{tabular}{l|c|l|c}
\hline \multicolumn{1}{c|}{ Acidentes Físicos } & Número & \multicolumn{1}{|c}{ Acidentes Humanos } & Número \\
\hline Fitotopônimos & 6 & Zootopônimos & 4 \\
\hline Zootopônimos & 4 & Fitotopônimos & 4 \\
\hline Ecotopônimos & 3 & Corotopônimo & 1 \\
\hline Hidrotopônimos & 2 & Ecotopônimo & 1 \\
\hline Não Classificado & 1 & & \\
\hline \multicolumn{1}{c|}{ Total } & & & $\mathbf{1 0}$ \\
\hline
\end{tabular}

Fonte: Elaboração das autoras.

1. Fitotopônimos ("topônimos de índole vegetal") (DICK, 1992, p. 31) - 10 ocorrências: Retiro Buriti; Fazenda Buriti (2); Fazenda Tarumã; Córrego Buriti (3); Córrego Pindaíba; Córrego Embarés e Córrego Pindaíba.

2. Zootopônimos ("topônimos de índole animal") (DICK, 1992, p. 32) - 8 ocorrências: Fazenda Araponga; Fazenda Arara; Fazenda Guanabi; Fazenda Jandaia; Córrego Jataí; Rio Sucuriú; Córrego Sucuri e Córrego Cateto.

3. Ecotopônimos ("topônimos relativos às habitações de um modo geral") (DICK, 1992, p. 33) - quatro ocorrências: Fazenda Taperão; Córrego Taperão; Córrego Tapera e Córrego Taperas.

4. Hidrotopônimos ("topônimos resultantes de acidentes hidrográficos em geral" (DICK, 1992, p. 31) - duas ocorrências: Represa Jupiá e Rio Paraná.

5. Corotopônimo ("topônimos relativos aos nomes de cidades, países, estados, regiões e continentes") (DICK, 1992, p. 32) - uma ocorrência: Fazenda Goytacazes.

6. Não Classificado - uma ocorrência: Córrego Imboraca. 
No corpus aqui analisado, 12 das categorias de Dick tiveram representação, cinco de natureza física e sete de cunho antropocultural, além de seis topônimos que não foram enquadrados no modelo adotado (Arapó, Cabajá, Araute, Morimolo, Jaraguaiá e Imboraca), em virtude de não terem sido localizadas fontes confiáveis que elucidassem o significado do item lexical investido de função toponímica (Cf. nota 10). As três categorias toponímicas mais produtivas nos quatro municípios em análise são de natureza física e são topônimos que valorizam espécies vegetais, animais e recursos hídricos: i) fitotopônimos com 112 ocorrências; ii) zootopônimos com 98 casos e iii) hidrotopônimos com 11 ocorrências ${ }^{12}$. As demais taxionomias identificadas no corpus estão assim distribuídas em termos de número de ocorrências: Ecotopônimos (10), Corotopônimos (10), Etnotopônimos (8), Mitotopônimos (6), Ergotopônimos (6), Antropotopônimos (3), Geomorfotopônimos (2), Litotopônimos (1) e Sociotopônimos (1).

Os fitotopônimos, a categoria mais produtiva, atestam a valorização, por parte do denominador, de plantas úteis para o seu cotidiano, seja pelo fornecimento de madeira (Fazenda Aroeira, Fazenda Ype, Sítio Taboca), seja pelo uso alimentar (córrego Maracujá, córrego Indaiá, córrego Macaúba, fazenda Jatobá, fazenda Bacuri, fazenda Guariroba), ou ainda pela utilidade da planta, como em córrego Buriti, tipo de palmeira cujas folhas são usadas nas coberturas das casas e as fibras, no artesanato. Em outras palavras, a grande incidência dos fitotopônimos justifica-se pela indiscutível importância dos vegetais para o homem, dando mostras de que a herança vocabular indígena, no léxico do português do Brasil, concentra-se, sobretudo entre os nomes relativos à vegetação, o que se reflete na toponímia.

Os dados analisados no âmbito deste trabalho ratificam, pois, a tese de que os topônimos motivados por elementos da flora são uma característica da toponímia de todo o território brasileiro. Nesse particular, Dick (1990, p. 145) ressalta que "o estudo da vegetação terrestre constitui, para o leigo, uma das mais árduas tarefas que se lhe possa propor, pela variedade das espécies que se entrecruzam em porções delimitadas do espaço geográfico analisado".

12 O Projeto ATEMS constatou, a partir do estudo dos topônimos rurais de acidentes físicos dos municípios sul-mato-grossenses, essas mesmas categorias como as mais produtivas só que na seguinte ordem: $1^{\circ}$ lugar: fitotopônimos; $2^{\circ}$ lugar: hidrotopônimos e $3^{\circ}$ lugar: zootopônimos. Cf. a esse respeito os estudos de Cazarotto (2020); Figueiredo (2020) e Pereira (2020). 
A segunda categoria mais produtiva no recorte toponímico analisado foi a dos zootopônimos. De acordo com Dick (1990, p. 263), a presença de animais entre as fontes motivadoras da toponímia brasileira reflete o fato de "os índios brasileiros dedicarem aos animais uma parte importante de sua cultura espiritual”. Como exemplos dessa categoria de topônimos citem-se, entre outros, Fazenda do Cateto, Córrego da Arara, Córrego Cupins, Córrego Perdizes, Fazenda Jandaia, Retiro Periquitos, Córrego Jataí, Rio Sucuriú, que valorizam espécies comuns na região que abriga esses topônimos. Observa-se, também entre os zootopônimos, que espécies comuns na fauna local funcionam como causa denominativa, tendência essa muito frequente tanto na toponímia sul-mato-grossense quanto no panorama toponímico das diferentes regiões brasileiras.

A terceira posição em termos de produtividade no corpus foi ocupada pelos hidrotopônimos, atestando a importância do elemento água como fator motivador na toponímia, essa característica marcante na toponímia é justificável pelo fato de a água ser um elemento indispensável para a sobrevivência humana.

Dick (1992, p. 66), ao discutir “os vocábulos toponímicos básicos de origem hidrográfica", fornece um panorama de topônimos formados com o água em diferentes posições no sintagma toponímico: Águas, Água Limpa, Águas Claras, Água Comprida etc. Embora não tenha sido registrada no corpus analisado a presença de topônimos formados com a unidade lexical água, ocorreu o registro de $\mathbf{1 1}$ topônimos formados por itens léxicos que remetem ao elemento água, como em Paraná (semelhante ao mar, do Tupi); Paranaíba (rio ruim, do Tupi); Ipanema (água ruim, imprestável, do Tupi); Paraúna (rio negro, do Tupi); Jupiá (remoinho que faz as águas de um rio, do Tupi), dentre outros.

Por fim, como anteriormente anunciado, os topônimos compostos híbridos com o segundo formante de base indígena que não foram computados para fins de classificação taxionômica, considerando que o primeiro formante do topônimo composto é o considerado para fins de classificação, foram reunidos no Quadro 1, a seguir, distribuídos segundo os quatro municípios que integram o espaço investigado. 
Quadro 1: Topônimos compostos híbridos com formante de base indígena como elemento especificador

\begin{tabular}{|c|c|c|c|}
\hline $\begin{array}{c}\text { Aparecida do } \\
\text { Taboado }\end{array}$ & Inocência & Paranaíba & Selvíria \\
\hline $\begin{array}{l}\text { (Foz) Rio } \\
\text { Paranaíba; }\end{array}$ & $\begin{array}{l}\text { (Fazenda) Cabeceira } \\
\text { do Bocaina }\end{array}$ & $\begin{array}{l}\text { (Fazenda) Cabeceira do } \\
\text { Bacuri }\end{array}$ & $\begin{array}{l}\text { (Fazenda) Vale do } \\
\text { Sucuri }\end{array}$ \\
\hline $\begin{array}{l}\text { (Ø) Passo da } \\
\text { Perereca }\end{array}$ & $\begin{array}{l}\text { (Fazenda) Cabeceira } \\
\text { do Moquém }\end{array}$ & $\begin{array}{l}\text { (Fazenda) Cabeceira do } \\
\text { Irara }\end{array}$ & $\begin{array}{l}\text { (Lagoa) Praia do } \\
\text { Rio Paraná }\end{array}$ \\
\hline $\begin{array}{l}\text { (Rio) Grande } \\
\text { (Jeticaí) }\end{array}$ & $\begin{array}{l}\text { (Fazenda) Cabeceira } \\
\text { do Mutunzinho }\end{array}$ & $\begin{array}{l}\text { (Fazenda) Cabeceira do } \\
\text { Ouricana }\end{array}$ & \\
\hline $\begin{array}{l}\text { (Fazenda) Alto } \\
\text { Paraná }\end{array}$ & $\begin{array}{l}\text { (Fazenda) Córrego da } \\
\text { Goiaba }\end{array}$ & $\begin{array}{l}\text { (Fazenda) Barrinha do } \\
\text { Ariranha }\end{array}$ & \\
\hline $\begin{array}{l}\text { (Retiro) Curva do } \\
\text { Maracujá }\end{array}$ & $\begin{array}{l}\text { (Fazenda) Córrego do } \\
\text { Mutum }\end{array}$ & $\begin{array}{l}\text { (Fazenda) Lagoa do } \\
\text { Araré }\end{array}$ & \\
\hline $\begin{array}{l}\text { (Fazenda) Nova dos } \\
\text { Cupins }\end{array}$ & $\begin{array}{l}\text { (Cachoeira) do Rio } \\
\text { Indaiá }\end{array}$ & $\begin{array}{l}\text { (Córrego) Cabeceira da } \\
\text { Samambaia }\end{array}$ & \\
\hline \multirow[t]{12}{*}{$\begin{array}{l}(\varnothing) \text { Barra das } \\
\text { Perobas }\end{array}$} & $\begin{array}{l}\text { (Fazenda) Reunidas do } \\
\text { Sucuriú }\end{array}$ & $\begin{array}{l}\text { (Fazenda) Barreirinho } \\
\text { da Ariranha }\end{array}$ & \\
\hline & $\begin{array}{l}\text { (Córrego) Cabeceira } \\
\text { da Tapera }\end{array}$ & $\begin{array}{l}\text { (Fazenda) Barreiro da } \\
\text { Ariranha }\end{array}$ & \\
\hline & $\begin{array}{l}\text { (Fazenda) Pouso do } \\
\text { Jaó }\end{array}$ & $\begin{array}{l}\text { (Ribeirão) Barreiro do } \\
\text { Ariranha }\end{array}$ & \\
\hline & $\begin{array}{l}\text { (Fazenda) S. José do } \\
\text { Córrego Tapera }\end{array}$ & (Fazenda) Alto Bacuri & \\
\hline & $\begin{array}{l}\text { (Fazenda) Santo } \\
\text { Antonio do Indaiá }\end{array}$ & $\begin{array}{l}\text { (Fazenda) Alto da } \\
\text { Ariranha }\end{array}$ & \\
\hline & $\begin{array}{l}\text { (Fazenda) S. Luiz do } \\
\text { Sucuriú }\end{array}$ & (Fazenda) Morro do Ipê & \\
\hline & $\begin{array}{l}\text { (Fazenda) S. José } \\
\text { Bocaina }\end{array}$ & & \\
\hline & (Fazenda) Rei dos Ipês & & \\
\hline & $\begin{array}{l}\text { (Fazenda) Pontal do } \\
\text { Indaiá }\end{array}$ & & \\
\hline & $\begin{array}{l}\text { (Fazenda) Nova } \\
\text { Xavantina }\end{array}$ & & \\
\hline & (Sítio) Cantar do Sabiá & & \\
\hline & $\begin{array}{l}\text { (Córrego) dos Três } \\
\text { Buritis }\end{array}$ & & \\
\hline
\end{tabular}

Fonte: Elaboração das autoras. 
Os resultados aqui apresentados atestam o significativo legado do Tupi no léxico do português brasileiro e, por extensão, na toponímia, sendo esse traço uma marca identificadora da toponímia brasileira. Os dados afiançam ainda a importância dos estudos toponímicos, justificada também por recuperarem múltiplas informações sobre a região investigada, o que fornece pistas sobre a análise da motivação dos nomes de lugares.

\section{Considerações finais}

Este estudo teve como propósito examinar aspectos da herança vocabular indígena incorporada ao sistema toponímico, mais especificamente na nomeação de espaços geográficos rurais pertencentes à microrregião de Paranaíba, estado de Mato Grosso do Sul.

A análise dos dados demonstrou a predominância das taxes de natureza física no universo toponímico examinado, o que pode ser justificado pela relação de proximidade entre o homem e o meio, como é o caso dos topônimos que remetem a elementos do ambiente, em especial, à flora, à fauna e à hidrografia. Justifica-se, assim, terem sido os fitotopônimos, os zootopônimos e os hidrotopônimos as taxes toponímicas com maior índice de ocorrência entre os 12 tipos identificados no corpus estudado.

A maior produtividade de topônimos motivados por elementos da flora e da fauna atesta a contribuição indígena para o léxico do português brasileiro, no que se refere à parcela incorporada pela toponímia. No caso da toponímia sul-mato-grossense, os nomes de plantas e de animais fornecidos pela população nativa aos colonizadores nos primeiros contatos com as populações autóctones também se perpetuam na toponímia.

Sublinhe-se também o significativo contingente de topônimos formados por unidades lexicais de base indígena em topônimos de estrutura simples (Córrego Taperas) e em nomes compostos híbridos, seja com o primeiro formante de origem indígena (Fazenda Ariranha de João Rosa), seja com a presença de item léxico oriundo de línguas ameríndias em outras posições da estrutura do sintagma toponímico (Fazenda Santo Antonio do Indaiá; Fazenda Alto da Ariranha). 
Em síntese, o estudo ratificou que a pesquisa toponímica ultrapassa o estudo de palavras, de etimologias, de significados retirados de dicionários. Por meio deste estudo foi possível recuperar aspectos etnolinguísticos e históricos das regiões estudadas, ratificando que o estudo dos nomes de lugares permite abstrair aspectos dos sentimentos do denominador, a sua expectativa frente à realidade e a maneira como o seu grupo lê e interpreta a realidade.

\section{REFERÊNCIAS}

ATEMS - Atlas Toponímico de Mato Grosso do Sul. (2017). Sistema de Dados. Campo Grande: UFMS (acesso restrito).

BORDONI, Orlando. Dicionário. A língua tupi na geografia do Brasil. Campinas (SP): Gráfica Muto Ltda, (s/d).

CARDOSO, Levy. Toponímia brasílica. Rio de Janeiro: Biblioteca do Exército Editora, 1961.

CAZAROTTO, Suely Aparecida. Fitotopônimos: influência da vegetação no processo de nomeação. In: ISQUERDO, Aparecida Negri (Org.). TOPONÍMIA. Tendências toponímicas no estado de Mato Grosso do Sul. V. II. Campo Grande: Editora UFMS, 2020, p. 65-91. Série Toponímia (no prelo).

CUNHA, Antônio Geraldo. Dicionário histórico das palavras portuguesas de origem tupi. 5. ed. São Paulo: Companhia Melhoramentos; Brasília: Universidade de Brasília, 1999.

DALGEL, Ana Paula Tribesse Patrício; ISQUERDO, Aparecida Negri. Projeto ATEMS: parâmetros metodológicos. In: ISQUERDO, Aparecida Negri (Org.). TOPONÍMIA: tendências toponímicas no estado de Mato Grosso do Sul, v. 2. Campo Grande/MS: Editora UFMS, 2020, p. 21-66 (Série Toponímia) (no prelo).

DICK, Maria Vicentina de Paula Amaral. Origens históricas da toponímia brasileira: os nomes transplantados. Revista do Instituto de Estudos Brasileiros, n. 24, p. 75-96, 1982. Disponível em: https://doi.org/10.11606/issn.2316-901X.v0i24p75-96. Acesso em 21 mar. 2020.

DICK, Maria Vicentina de Paula Amaral. A motivação toponímica e a realidade brasileira. São Paulo: Edições Arquivo do Estado, 1990.

DICK, Maria Vicentina de Paula Amaral. Toponímia e Antroponímia no Brasil. Coletânea de Estudos. São Paulo: Serviço de Artes Gráficas/FFLCH/USP, 1992.

DICK, Maria Vicentina de Paula Amaral. Toponímia e Línguas Indígenas do Brasil. Estudos Avançados, São Paulo, v. 8, n. 22, p. 435-436, dez. 1994. Disponível em: < http://www.scielo.br/pdf/ea/v8n22/59.pdf>. Acesso em 21 mar. 2020.

DRUMOND, Carlos. Contribuição Bororo à toponímia brasílica. São Paulo: Editora da USP, 1965. 
FIGUEIREDO, Carla Regina de Souza. Os hidrotopônimos de Mato Grosso do Sul: o que os dados do ATEMS revelam. In: ISQUERDO, Aparecida. Negri. (Org.). TOPONÍMIA. Tendências toponímicas no estado de Mato Grosso do Sul. V. II. Campo Grande: Editora UFMS, 2020, p. 93-119. Série Toponímia (no prelo).

INSTITUTO BRASILEIRO DE GEOGRAFIA E ESTATÍSTICA (IBGE). 2010. Disponível em: <http://www.ibge.gov.br/>. Vários acessos.

ISQUERDO, Aparecida Negri; FIGUEIREDO, Carla Regina de Souza. Corotopônimos na toponímia sul-mato-grossense: reflexões teórico-metodológicas. Papéis, Campo Grande, v. 16, n. 31, Especial ABRALIN, 2012. Disponível em: http://www.papeis.ufms.br/Revista_Papeis_V16_N31.pdf. Acesso em 22 jun.2020.

ISQUERDO, Aparecida Negri. Herança lusa na toponímia de municípios da região Norte do Brasil: perspectivas linguística e sócio-histórica. COLUCCIA, Rosario; BRINCAT, Joseph M.; MÖHREN, Frankwalt (éd.) (2016): Actes du XXVIIe Congrès international de linguistique et de philologie romanes (Nancy, 15-20 juillet 2013). Section 5: Lexicologie, phraséologie, lexicographie. Nancy/France: ATILF/SLR, 2016, p. 315-328. Disponível em: http://www.atilf.fr/cilpr2013/actes/section-5.html. Acesso em 22 mar. 2019.

NAVARRO, Eduardo de Almeida. Dicionário de tupi antigo: a língua indígena clássica do Brasil. São Paulo: Global, 2013.

PEREIRA, Renato Rodrigues. Zootopônimos: a fauna e seu reflexo na toponímia de Mato Grosso do Sul. In: ISQUERDO, Aparecida Negri. (Org.). Toponímia. Tendências toponímicas no estado de Mato Grosso do Sul. V. II. Campo Grande: Editora UFMS, 2020, p. 121-136. Série Toponímia (no prelo).

SAMPAIO, Teodoro. O tupi na geografia nacional. 3. ed. Bahia: Secção Graphica da escola de Aprendizes Artificies, 1928.

SOUZA, Bernardino José de. Dicionário da terra e da gente do Brasil. São Paulo: Cia. Ed. Nacional, 1961.

TIBIRIÇÁ, Luíz Caldas. Dicionários de topônimos de origem tupi: significado dos nomes geográficos de origem tupi. São Paulo: Traço Editora, 1985.

TIBIRIÇÁ, Luíz Caldas. Dicionário Guarani Português. São Paulo: Traço Editora. 1989. 